\title{
Two year cumulative incidence of trunk abnormalities in a schoolpopulation in Rotterdam, The Netherlands
}

\author{
ALICE A.J.M. HAZEBROEK-KAMPSCHREUR, ALBERT HOFMAN, AD PH. VAN DIJK, BERT VAN LINGE *
}

\begin{abstract}
We conducted a study of the 2 year cumulative incldence of trunk abnormalities in a cohort of 3,071 11 year old children (1,621 boys, $1,450 \mathrm{girls}$ ). The following data were recorded: height, weight, signs of puberty and menarche. Trunk abnormality was assessed in the erect child (asymmetry of shoulders and waistline, imbalance of the trunk, scoliosis, lordosis, kyphosis, swayback and flexibility) and by the forward bending test (FBT) (rib hump or lumbar prominence, persisting scollosis, kyphosis and deviant lateral aspect). A normal FBT both at baseline and at follow-up was found in $84 \%$ of the boys and in $79 \%$ of the girls. The 2 year cumulative indidence of an abnormal FBT was $10 \%$ in boys and $13 \%$ in girls.
\end{abstract}

Key words: school screening, scoliosis, trunk asymmetry

$\Gamma_{\text {runt }}$

runk abnormalities in children, such as scoliosis and kyphosis, have been widely studied. School screening programmes for scoliosis have provided insight into the prevalence and incidence and the natural history. However, in many studies prevalence and incidence data are mixed. Prevalence refers to the number of individuals with the disease existing at any time as a proportion of the number exposed to that risk. The cumulative incidence provides a good estimate of the risk of developing the disease during a specified period of time. In addition, methods of diagnosing trunk abnormalities are different in the various studies. Some are based on full clinical examination by physicians, others only on the forward bending test $(1 \mathrm{~min}$ test) by school nurses or trained laymen.

There is no consensus about the most appropriate age for scoliosis screening. In many countries $10-16$ year old children are screened annually. In Rotterdam, The Netherlands, no specific screening programme for scoliosis is performed, but all school children are invited for full medical examination by school physicians at the age of 11 years and in the second grade of secondary education (age 13-14 years).

We conducted a prospective follow-up study of trunk abnormalities in a cohort of 11 year old children to obtain prevalence and 2 year cumulative incidence data. The

-A.A.J.M. Hazebroek-Kampschtreur ${ }^{1,23}$, A. Hofman' ${ }^{2}$ A.Ph. van Dfjk', B. van Unge'

1 Department of Eptdemlology, Municjpal Health Servkce, Rotterdam, The Netherlands

2 Department of Epidemiology and Biostatistica, Erasmus University Medkal School, Rotterdam. The Netherlands

3 Department of Orthopaedic Surgery, University Hospltal Rotterdem, Rotterdam, The Netherlands

Correspondence: A.AJM. Hazebroek-Kampschreur, MD, PhD, Munkdpal

Health Service Rotterdarn, Department of Epldemtology, P.O. Box 70032. 3000 LP Rotterdam, The Netherlandk, tet +31 104339620, fax +31104339493 results of the prevalence study in 11 year old children have already been described. ${ }^{1}$ We now report the 2 -year cumulative incidence of trunk abnormalities in the same cohort.

\section{METHODS}

Subjects

The study was embedded in the regular medical examination of the second grade of secondary school, between September 1986 and July 1987. All school children in Rotterdam, born in 1973, who had participated in the prevalence study $(1984 / 1985)$ were eligible for follow-up. Of the approximately 6,000 second grade students, 4,663 children were born in 1973. In 3,071 children, data of baseline examination were present, that is $62 \%$ of the initial study group of 4,915 children. Mean age at followup was 13 years and 7 months and $53 \%$ of the children were male. A number of the eligible children were examined later than August 1987 and were considered as lost to follow-up in the present study. Reasons for lost to follow-up were moving home or going to a school outside Rotterdam or not responding to the invitation for the optional examination twice. There was no difference in baseline characteristics between the follow-up and lost to follow-up groups (detailed information on request). An abnormal FBT at baseline examination was noted in 252 (8\%) of the children; in more than half of these, the FBT was normal at follow-up examination.

\section{Measurements}

Although the school physicians were experienced in the physical examination of the trunk, including the forward bending test as being part of the regular examination, they received oral, audiovisual and written training and demonstration of patients prior to the study to guarantee 
standardization of measurements. All the family physicians and orthopaedic surgeons in Rotterdam were informed. The following measurements were the objectives of the study: height in centimetres and weight in $0.1 \mathrm{~kg}$. Physical maturity was ascertained by assessing testis development in boys, breast development and menarche in girls, pubic hair development and onset of the rapid growth spurt in both sexes. Grading was performed according to Tanner. ${ }^{2}$ First, pelvic tilt was looked for and leg length inequality was corrected by placing 1 or more boards of $0.5 \mathrm{~cm}$ under the short leg until horizontal symmetry of the iliac crests and posterior iliac spines was obtained. The correction was noted in centimetres. After correction, the standing child was observed from the front and the back for any obvious deformities such as asymmetry of the shoulders, scapulae and waistline. The balance of the thorax over the pelvis was assessed with a plumbline. Flexibility of the spine was examined in flexion, extension and sidebending. The standing child was viewed from the side for areas of hyper-or hypolordosis and hyper-or hypokyphosis. Trunk asymmetries and abnormal curvatures in the median plane in the upright position were recorded as either absent or present, according to the proposed limits for structural trunk asymmetries by Vercauteren et al. ${ }^{3}$ The forward bending test was performed, with the child standing with knees straight and feet together, bending at the waist with arms hanging and palms together. The back was viewed from the child's head and both sides were compared for symmetry from the upper thoracic area to the lumbosacral area. The spine was also viewed from the side in the forward bending position to evaluate the contour of the back for kyphotic angulation. Flexibility of hyperkyphosis was also tested by prone hyperextension. Flexibility of lordosis was shown in the FBT and also with the child bending in a knee-chest position. The following $4 \mathrm{com}$ ponents of the FBT were listed as either absent or present.

- Rib humps and lumbar prominences as signs of vertebral rotation. A rib hump is not always associated with a scoliosis in upright position.

- Persistence of the standing scoliosis, in order to discriminate between postural and structural scoliosis. It will usually be associated with a rib hump or lumbar prominence.

- Correctability of the kyphosis, in order to discriminate between postural and struc. tural kyphosis.

- Deviant lateral aspect.

We considered a FBT as abnormal if at least 1 of the 4 components was present.
Children with distinct trunk abnormalities who needed further assessment were referred to the family physician and/or orthopaedic surgeon. Children with lesser trunk abnormalities were not referred; they were re-examined by the school physician 6-12 months later.

\section{Data analysis}

Prevalence of anthropometrical measurements was calculated. Analysis of the 2 year cumulative incidence of trunk abnormalities was based on 2,819 children free of trunk abnormalities at baseline examination; 252 subjects with trunk abnormalities at baseline examination were excluded. The 2 year cumulative incidence was calculated for each trunk abnormality separately, as well as for a positive FBT.

\section{RESULTS}

Anthropometrical data of baseline and follow-up examinations are given in table 1. Table 2 shows prevalence of clinical findings at baseline and 2 years later. Table 3 shows the 2 year cumulative incidence of trunk abnormalities and of abnormal FBT. Scoliosis in upright position was found in $84(5.6 \%)$ of the boys and $80(6.1 \%)$ of the girls and did not disappear on forward bending in 36 (2.4\%) and 46 (3.5\%) respectively. A rib hump or lumbar prominence was found in 107 (7.1\%) of the boys and 127 (9.7\%) of the girls. An abnormal FBT was found in 152 $(10.1 \%)$ and $170(13.0 \%)$ respectively.

\section{DISCUSSION}

In our prospective follow-up study, embedded in the current school health care programme, $62 \%$ of the initial cohort of 11 year old children were examined for follow-up. In regard to baseline characteristics, there was no differ-
Table 1 Anthropometric characteristics at baseline and at 2 year follow-up examinations

\begin{tabular}{ccccc}
\hline & \multicolumn{2}{c}{ Boys (n=1,621) } & \multicolumn{2}{c}{ Girls (n=1,450) } \\
& $\begin{array}{c}\text { Baseline } \\
\text { Age 11 years }\end{array}$ & $\begin{array}{c}\text { Follow-up } \\
\text { Age 13 years }\end{array}$ & $\begin{array}{c}\text { Baseline } \\
\text { Age 11 years }\end{array}$ & $\begin{array}{c}\text { Follow-up } \\
\text { Age 13 years }\end{array}$ \\
\hline Paramerer & $147.6(7.2)^{\mathbf{2}}$ & $162.4(9.1)$ & $149.3(7.8)$ & $161.7 \quad(7.4)$ \\
Reight (cm) & $128-175$ & $137-197$ & $125-172$ & $134-182$ \\
Weinge & $38.0(7.7)$ & $50.5(10.7)$ & $39.9(8.5)$ & $52.4(10.1)$ \\
Weight (kg) & $22.1-96.0$ & $26.5-99.8$ & $20.0-84.5$ & $26.0-99.8$ \\
Range & 20.8 & 62.9 & 50.4 & 87.3 \\
Start of growth spurt (\%) & & & & \\
Breast/testis development (\%) & & 6.1 & 28.8 & 1.0 \\
Stage 1 & 66.2 & 27.4 & 39.3 & 6.0 \\
2 & 29.8 & 31.7 & 23.4 & 21.1 \\
3 & 3.8 & 29.3 & 7.9 & 42.5 \\
4 & 0.2 & 5.4 & 0.6 & 29.5 \\
5 & 0.0 & & & \\
Pubic hair development (\%) & & 12.2 & 42.1 & 1.7 \\
Stage 1 & 73.4 & 27.7 & 31.8 & 8.2 \\
2 & 24.1 & 28.5 & 18.7 & 20.5 \\
3 & 2.4 & 6.5 & 42.6 \\
4 & 0.2 & 26.0 & 6.5 & 25.6 \\
5 & 0.0 & 4.8 & 0.8 & 1.4 \\
6 & 0.0 & 0.9 & 0.1 & 73.8 \\
\hline
\end{tabular}

a Standard deviation 
ential lost to follow-up. Compared to the 1980 biometrical survey, ${ }^{4}$ the mean height and weight of boys were nearly the same while girls were heavier and slightly shorter.

The principal finding of our study is that the cumulative incidence and thereby the absolute risk for trunk abnormalities is $11 \%$. Most studies of adolescent idiopathic scoliosis are based on annual screening programmes in 10-15 year old children and data concern mostly prevalence, not cumulative incidence. Our survey was conducted in 1 birth cohort. All children were examined twice: i) in a pre-puberty or early puberty phase at age 11 years and ii) in a puberty phase at age 13 years. Prevalences

Table 2 Prevalence (\%) of trunk abnormalities at baseline (age 11 years) and at 2 year follow-up (age 13 years)

\begin{tabular}{|c|c|c|c|c|}
\hline \multirow[b]{2}{*}{ Parameter } & \multicolumn{2}{|c|}{ Boys (n=1,621) } & \multicolumn{2}{|c|}{ Girls $(n=1,450)$} \\
\hline & $\begin{array}{l}\text { Baseline } \\
\text { Age } \\
11 \text { years }\end{array}$ & $\begin{array}{c}\text { Follow-up } \\
\text { Age } \\
13 \text { years }\end{array}$ & $\begin{array}{c}\text { Baseline } \\
\text { Age } \\
11 \text { years }\end{array}$ & $\begin{array}{l}\text { Follow-up } \\
\text { Age } \\
13 \text { years }\end{array}$ \\
\hline Pelvic tilt & 9.1 & 13.1 & 8.7 & 11.6 \\
\hline $\begin{array}{l}\text { Asymmetry of } \\
\text { shoulders }\end{array}$ & 4.1 & 7.5 & 6.1 & 7.8 \\
\hline $\begin{array}{l}\text { Asymmetry of } \\
\text { waistline }\end{array}$ & 5.2 & 11.5 & 7.6 & 11.3 \\
\hline Imbalance of trunk & 1.1 & 3.5 & 1.7 & 3.1 \\
\hline Scoliosis & 4.4 & 6.4 & 5.4 & 8.8 \\
\hline Lordosis & 2.3 & 2.5 & 4.4 & 3.7 \\
\hline Kyphosis & 3.9 & 6.6 & 2.9 & 6.4 \\
\hline Swayback & 0.7 & 1.0 & 0.6 & 0.9 \\
\hline Impaired flexibility & 0.3 & 1.5 & 0.8 & 1.4 \\
\hline \multicolumn{5}{|l|}{ Forward bending test } \\
\hline Prominence & 4.3 & 8.6 & 6.1 & 12.3 \\
\hline $\begin{array}{l}\text { Persistence of } \\
\text { scoliosis }\end{array}$ & 3.3 & 3.0 & 4.3 & 5.2 \\
\hline $\begin{array}{l}\text { Non-correctable } \\
\text { kyphosis }\end{array}$ & 0.2 & 1.1 & 0.3 & 1.1 \\
\hline $\begin{array}{l}\text { Deviant lateral } \\
\text { aspect }\end{array}$ & 2.5 & 2.3 & 2.8 & 2.6 \\
\hline
\end{tabular}

Table 3 Two year curnulative incidence (\%) of trunk abnormalities and of abnormal forward bending test in 2,819 13 year old children previously free of trunk abnormalities

\begin{tabular}{lccc}
\hline Parameter & $\begin{array}{c}\text { Boys } \\
\mathrm{n}=1,507\end{array}$ & $\begin{array}{c}\text { Girls } \\
\mathrm{n}=1,312\end{array}$ & $\begin{array}{c}\text { Total } \\
\mathrm{n}-2,819\end{array}$ \\
\hline Pelvic tilt & 9.2 & 8.0 & 8.7 \\
Asymmetry of shoulders & 6.8 & 6.0 & 6.5 \\
Asymmetry of waistline & 10.4 & 9.1 & 9.8 \\
Imbalance of trunk & 2.7 & 2.1 & 2.4 \\
Scoliosis & 5.6 & 6.1 & 5.8 \\
Lordosis & 1.9 & 2.8 & 2.4 \\
Kyphosis & 5.4 & 5.8 & 5.6 \\
Swayback & 0.7 & 0.8 & 1.0 \\
Impaired flexibility & 1.2 & 0.8 & 1.0 \\
Forward bending test & & & \\
$\quad$ Prominence & 7.1 & 9.7 & 8.3 \\
$\quad$ Persistence of scoliosis & 2.4 & 3.5 & 2.9 \\
$\quad$ Non-correctable kyphosis & 0.7 & 0.9 & 0.8 \\
$\quad$ Deviant lateral aspect & 1.4 & 1.5 & 1.5 \\
Abnormal on forward & & & \\
bending test & 10.1 & 13.0 & 11.4 \\
\hline
\end{tabular}

at ages 11 and 13 years in our study were similar to prevalences of 10-20\% of the first tier of scoliosis screening programmes and the prevalence increased with age. ${ }^{5-7}$ However, we found that the prevalence in the examination at age 13 years mainly consisted of the 2 year cumulative incidence. Chan et al. ${ }^{8}$ found in retrospect that 21 out of 49 scoliosis patients had been symmetric at an earlier screening.

As in most studies, we used an abnormal FBT as an alerting sign for a structural deformity. Many children with an abnormal FBT will have mild and non-progressive or resolving scoliosis, but some children will have curves that progress. It is impossible to separate progressive from non-progressive scoliosis on the basis of one clinical examination; physical growth and maturation has also to be considered. Regression of scoliosis has been described by various authors. ${ }^{5,9,10}$ In their groups of scoliosis patients, spontaneous improvement or regression had occurred in $3-22 \%$ and in approximately half of the patients the magnitude of the curvatures had remained unchanged. In our study group, one-half to two-thirds of the children with an abnormal FBT at age 11 years had improved to normal at age 13 years. Only a few of these children had been referred for further assessment; most children referred after the first examination did have an abnormal FBT at both measuring moments.

What do our findings mean for school health programmes? It appears necessary to perform at least 2 examinations for trunk abnormalities during adolescence. Referral on 1 sole examination, i.e. 1 abnormal FBT, should only be done in the case of distinct findings; in the case of less distinct findings re-examination in 6 months is necessary.

\section{REFERENACES}

1 Hazebroek-Kampschreur AAM, Hofman A, Dijk APh van, Linge B van. Prevalence of trunk abnormalities in eleven-year-old schoolchildren in Rotterdam, The Netherlands. J Pediatr Orthop 1992; 12:480-4.

2 Tanner JM. Growth at adolescence. Oxford: Blackwell Scientific Publications, 1962:32-9.

3 Vercauteren $M$, Beneden $M$ van, Verplaetse $R$, Croene $P h$, Uyttendaele D, Verdonk R. Trunk asymmetries in a Belgian school population. Spine 1982;7:555-62.

4 Roede MJ, Wieringen JC van. Growth diagrams 1980 Netherlands third nation-wide survey. Tijdschr Soc Gezondheidsz 1985;63(Suppl):1-34.

5 Brooks HL, Azen SP, Gerberg E, Brooks R, Chan L. Scoliosls: a prospective epidemiological study. J Bone Joint Surg [Am] 1975;57:968-72.

6 Morais T, Bernier M, Turcotte F. Age- and sex-specific prevalence of scoliosis and the value of school screening programs. Am J Public HIth 1985;75:1377-80.

7 Pessers FGM, Florack EIM, Zielhuis GA. is screening op scoliose aan te bevelen? Tijdschr Soc Gezondheidsz 1986;64:451-5.

8 Chan A, Moller J, Vimpani G, Patterson D, Southwood R, Sutherland A. The case for scoliosis screening in Australian adolescents. Med J Aust 1986;145:379-83.

9 Li High Pin, Liu Yong Mo, Li Lin, et al. Earty diagnosis of scoliosis based on school-screening. J Bone Joint Surg [Am] 1985;67:1202-5.

10 Rogala E, Drummond DS, Gurr J. Scollosis: incidence and natural history. J Bone Joint Surg [Am] 1978;60:173-6.

Received 3 Februory 1994, accepted 5 September 1994 